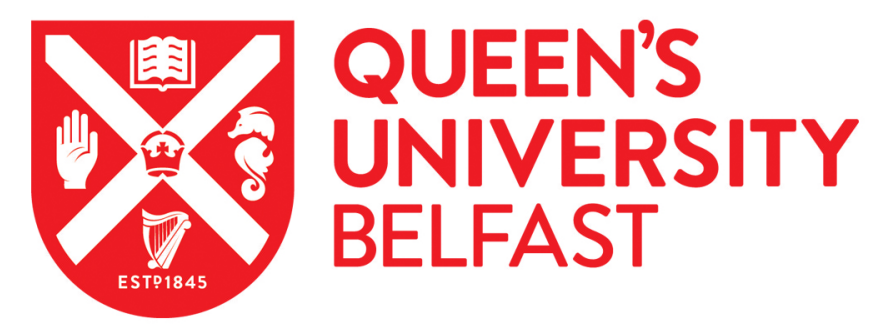

\title{
Quantification of wind curtailment on a medium-sized power system and mitigation using municipal water pumping load
}

Davison-Kernan, R., Liu, X., McLoone, S., \& Fox, B. (2019). Quantification of wind curtailment on a mediumsized power system and mitigation using municipal water pumping load. Renewable and Sustainable Energy Reviews, 112, 499-507. https://doi.org/10.1016/j.rser.2019.06.004

Published in:

Renewable and Sustainable Energy Reviews

Document Version:

Peer reviewed version

Queen's University Belfast - Research Portal:

Link to publication record in Queen's University Belfast Research Portal

\section{Publisher rights}

Copyright 2019 Elsevier.

This manuscript is distributed under a Creative Commons Attribution-NonCommercial-NoDerivs License

(https://creativecommons.org/licenses/by-nc-nd/4.0/), which permits distribution and reproduction for non-commercial purposes, provided the author and source are cited.

\section{General rights}

Copyright for the publications made accessible via the Queen's University Belfast Research Portal is retained by the author(s) and / or other copyright owners and it is a condition of accessing these publications that users recognise and abide by the legal requirements associated with these rights.

Take down policy

The Research Portal is Queen's institutional repository that provides access to Queen's research output. Every effort has been made to ensure that content in the Research Portal does not infringe any person's rights, or applicable UK laws. If you discover content in the Research Portal that you believe breaches copyright or violates any law, please contact openaccess@qub.ac.uk. 


\title{
Quantification of wind curtailment on a medium-sized power system and mitigation using municipal water pumping load
}

\author{
R. Davison-Kernan*, X. Liu, S. McLoone, B. Fox \\ School of Electronics, Electrical Engineering and Computer Science, Queen's University Belfast
}

\begin{abstract}
The issues of climate change and dependence on fuel imports as well as a good local wind resource have led to a significant expansion of wind generation on the power system of Ireland in recent years, with further development planned. As it operates on a relatively small and isolated system, Irish wind generation must be carefully managed to mitigate its variable nature. This could lead to significant curtailment of wind power for system stability reasons, undermining the economic case for wind generation and reducing its effectiveness at displacing traditional, fossil-fired generation.

This work quantifies the potential curtailment that might be seen on the future Irish and other power systems under several different scenarios, and presents Demand Side Management (DSM) as a tool to reduce curtailment. DSM of a water supply system is investigated to this end, as well as the inputs that would be necessary for such a system in order to benefit both the water system operator and the power system as a whole.

Keywords: Demand Side Management, Wind Power, Curtailment, Real Time Pricing, Optimisation, Water Pumping
\end{abstract}

\section{Introduction}

Wind generation has seen significant expansion in recent years [1]. In 2018, 30\% of all electricity on the island of Ireland was supplied by wind [2]. Both jurisdictions on the island of Ireland (Northern Ireland and the Republic of Ireland) have a target of $40 \%$ of electricity from renewable sources by 2020 [3], and although this is unlikely to be met in time, it is still the medium-term aspiration of the system.

Ireland is a relatively small and isolated power system with a peak demand of approximately $6.8 \mathrm{GW}$ and interconnection capacity of $750 \mathrm{MW}$ [4]. The variable and stochastic nature of wind generation poses challenges for

\footnotetext{
${ }^{*}$ Corresponding author Permanent address: SONI Ltd., Castlereagh House, 12 Manse Road, Belfast, BT6 9RT, N. Ireland

Email address: ronan.kernan@soni.1td.uk (R. Davison-Kernan) 
Transmission System Operators (TSOs), as unexpected transients can lead to a shortfall or surplus in generation and issues with ramping conventional generators [6]. The non-synchronous nature of the wind generators used can lead to a shortfall in system inertia, meaning more severe transients during loss of load or loss of generation events. To ensure system stability it can be necessary to constrain the output from wind generators - whether for local network reasons (referred to as constrained wind) or for overall power system stability (referred to as curtailment) [7].

In order to bolster system stability, both TSOs in Ireland (EirGrid and SONI [System Operator Northern Ireland]) have instituted a limit on System Non-Synchronous Pentration (SNSP). This currently stands at 65\%, with a hope that it may be increased in the future [3], [8]. SNSP is defined as follows:

$$
\mathrm{SNSP}=\frac{\text { wind generation }+ \text { interconnector (HVDC) imports }}{\text { system demand }+ \text { interconnector (HVDC) exports }}=\frac{W+I}{D+E}
$$

Wind power potential does occasionally exceed the SNSP limit, and $4.1 \%$ of all potential wind power was dispatcheddown in 2014, of which approximately $65 \%$ was curtailed, with the rest due to network constraints [9]. As the installed capacity of wind generation rises, the amount of wind energy curtailed will also almost certainly increase. In order to reach the target of $37 \%$ of all electricity from wind, it has been suggested that wind penetrations of up to $75 \%$ would have to be permitted to prevent unacceptable levels of curtailment [3].

In the SEM, wind generators were paid for curtailed energy as if it were not curtailed. This is no longer the case in ISEM but wind generators still receive subsidy payments for curtailed wind and are paid for wind constrained for network reasons. Ending these payments would reduce the attractiveness of wind generation as an investment for developers. Either scenario undermines the economic case for wind generation [10].

A number of studies have been undertaken to estimate the magnitude of curtailment on the 2020 Irish power system. Martin-Almenta et al. in [7] found that significant reductions in curtailment could be achieved by increasing the SNSP limit to $75 \%$. McGarrigle and Leahy in [10] investigated the effect of relaxing various operational constraints on curtailment and system costs on a hypothetical Irish power system with a wind penetration of $32 \%$. They found that wind curtailment of between $6 \%$ and $7 \%$ was achievable through increasing the SNSP limit to $75 \%$, with levels as low as $4 \%$ possible through relaxation of local system constraints.

Total elimination of curtailment would be impractical - there might be times when wind penetrations could exceed 
$100 \%$ of the total system load, in which case curtailment could not be avoided. Interconnection between Ireland and Britain is asynchronous (HVDC), limiting the scope for export. Equation 1 reflects the need to provide sufficient inertia in the Irish system to limit post-outage rate of change of frequency. Taking the aspirational value for SNSP of $75 \%$, the export limit of $750 \mathrm{MW}$ would limit wind generation for a typical demand of $4000 \mathrm{MW}$ to $3563 \mathrm{MW}$. The commercial factors militating against extra transmission investment are outlined in Section 5.3.3.1 of [17]. It follows that there must be an acceptable level of curtailment. This has been set at 5\% by EirGrid [11]. 5\% of all wind energy curtailed does not necessarily represent a 5\% loss of all wind energy in economic terms - wind curtailment usually occurs at times of low System Marginal Price (SMP), as can be seen in Figure 1. This figure shows a heatmap of the frequency and magnitude of curtailment for all 30-minute market intervals in 2014, when SNSP was set at 50\%. Curtailment was most common at SMP values of below $£ 50 / \mathrm{MWh}$. Since the distribution of curtailment is skewed towards lower values of SMP, $5 \%$ curtailment by energy is likely to equate to less than $5 \%$ of the total economic value of all wind generation. This is discussed further in Section 2.

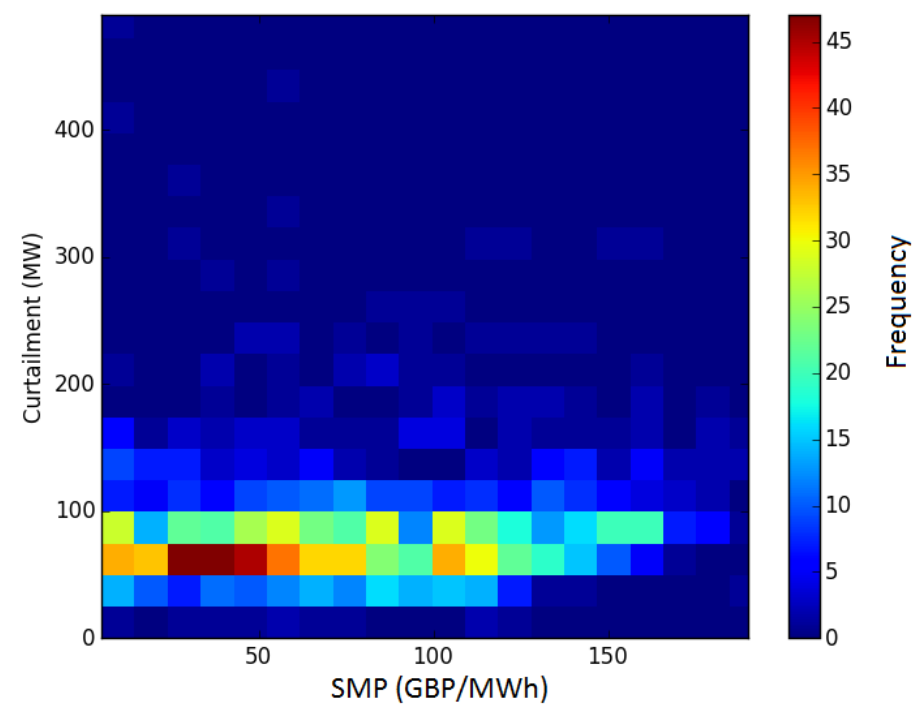

Figure 1: Relation of curtailment instances in 2014 to SMP and curtailment magnitude. SNSP $=50 \%$

The capacity factor of wind generation in Ireland is approximately 30\% [9]. Achieving wind penetrations greater than this capacity factor is likely to be difficult without increased use of energy storage or demand-side participation [17]. Tuohy et al. in [18] found that storage would not become economical from a system perspective until average wind penetrations of greater than $40 \%$ were achieved, and that storage was operated based mainly on the load profile rather than on wind generation until high levels of wind were seen. Storage is also inherently inefficient, with the most 
mature technologies (such as pumped storage hydroelectric schemes) offering turn-around efficiencies of no greater than $85 \%$ [18].

Demand Side Management (DSM) offers an opportunity to maximise the usage of existing assets by dispatching load not just on the basis of consumer demand but also to support the operation of the power system. Flexible demand can act as a form of reserve [20], and loads can be scheduled in order to minimise cost by following a Real Time Pricing (RTP) tariff based on SMP or to provide ancillary services. By reducing the need for polluting generators at peak times, DSM can also be used to reduce greenhouse gas emissions [21]. A detailed summary of DSM and demand response schemes can be found in [22] and [23]. Where DSM has been carried out based on energy cost, it has primarily been on the basis of time-variant Time of Use (ToU) pricing [12][13][14]. ToU tariffs do not track the actual market price of electricity and thus do not provide an incentive for consumers to respond to specific events, such as generator outages or high-wind scenarios [15]. Increased penetrations of variable generation such as wind generation mean that price peaks do not always occur at the same time of day, as high penetrations of low marginal cost generation during peak times reduce the need for low merit generation, thus, in theory, reducing market prices [16]. An RTP tariff, based on the wholesale cost of electricity, offers a realistic means of tracking the non-routine variations in system price.

One particular application of DSM of interest to power systems with high penetrations of variable generation is demand which can be scheduled to mitigate this variability [17]. Scheduling demand to coincide as much as possible with wind generation would allow increased uptake of wind. By increasing demand during high wind scenarios, the amount of wind generation allowed below the SNSP limit would increase accordingly. DSM is frequently seen as 'negative generation', with flexible load being dispatched by the TSO. This requires the aggregation of smaller loads into larger 'units' so that they are of sufficient size to merit inclusion in system scheduling. An alternative approach is a more passive, market-driven mode whereby flexible loads would pay a tariff proportional to some variable of the power system. Such loads, if scheduled on the basis of a changing price, would then modify their loads to take advantage of the changes in price relating to this variable.

This work provides an estimation of the potential curtailment that may be seen on the future Irish power system (Section 2) under a number of different SNSP scenarios. Interconnection has been suggested as a means to reduce curtailment - however this work highlights HVDC interconnection as a potential source of increased curtailment rather than a means to mitigate it. The impact of DSM on curtailment has not been investigated before, and so the potential impact on wind curtailment of DSM using municipal water supply as a representative system is investigated in 
Section 3 under different optimisation regimes. Section 4 discusses a modified version of RTP in order to encourage curtailment mitigation by flexible loads.

\section{Curtailment quantification}

In order to assess the impact that DSM of a flexible load could have on curtailment in a future Irish power system, it was first necessary to quantify the level of curtailment that might be expected on such a system. In order to meet the $40 \%$ renewable energy target mentioned in Section 1, both jurisdictions in Ireland have a target of 37\% penetration of wind generation on the power system, and so this was used as the basis for the study. Wind generation data were taken from 2013 and 2014 (two years where wind speeds were broadly representative of the local average) and scaled up to $37 \%$ penetration, and curtailment analysed for both sets of data at different SNSP levels. Average wind penetration was $17 \%$ in 2013, and $20 \%$ in 2014. It was important in this work to use data that represent wind power potential. Hence wind energy curtailment should be minimal. The years 2013 and 2014 provide a compromise between realistic market price variation and modest curtailment - 1.4\% in 2013 and 2.7\% in 2014. All data were taken from EirGrid and SONI [4].

Curtailment also occurs due to a number of factors other than the SNSP limit including reserve provision and voltage control requirements. These were not included in this analysis, but frequently occur at the same time the SNSP limit would be in effect [9].

Local constraints were not included in this analysis. The scaled-up load curve for 2013 was applied to the interconnector and wind data from that year, and the curtailment quantified by applying a series of different SNSP values, from $50 \%$ to $80 \%$ in $5 \%$ steps. Interconnector capacity was assumed to be $750 \mathrm{MW}$, as it is currently. The same analysis was carried out on the 2014 data.

System price was also taken from the year being analysed. While these prices (and interconnector flows) would likely change in a future Irish power system with higher wind penetrations, price trends would be the same - lower prices during periods of very high wind, for example. Thus the changes seen in the value of curtailed energy should be broadly representative.

When implemented on a large scale, DSM would most likely have an impact on the SMP itself. Work carried out in 
parallel to this study [5] showed that small changes in demand had negligible effect on SMP and therefore such an effect was not considered.

The analysis of the scaled 2013 data can be seen in Table 1, and the 2014 data in Table 2 . The value $(V)$ of curtailed energy seen in both tables was the sum of the amount of energy curtailed multiplied by the SMP during periods when curtailment was taking place, as described by Equation 2.

$$
V=\sum_{i=1}^{17520} \mathrm{SMP}_{i} L_{i}
$$

$\mathrm{SMP}_{i}$ is the SMP (£/MWh) during period $i$ and $L_{i}$ is the energy lost to curtailment (MWh) during period $i$, for all 1752030 minute periods in a year.

Table 1: 2013 wind data scaled to $37 \%$ average penetration

\begin{tabular}{|c|c|c|c|c|c|c|c|}
\hline SNSP limit & $\mathbf{5 0 \%}$ & $\mathbf{5 5 \%}$ & $\mathbf{6 0 \%}$ & $\mathbf{6 5 \%}$ & $\mathbf{7 0 \%}$ & $\mathbf{7 5 \%}$ & $\mathbf{8 0 \%}$ \\
\hline Hours of curt. & 3629 & 3181 & 2768 & 2368 & 1986 & 1578 & 1206 \\
\hline Curt. energy (GWh) & 3264 & 2607 & 2034 & 1540 & 1123 & 786 & 529 \\
\hline Value, curt. energy (£m) & 159 & 124 & 94 & 68 & 48 & 31 & 20 \\
\hline Value, all wind (£m) & \multicolumn{7}{|c|}{12658} \\
\hline Magnitude, all wind (GWh) & \multicolumn{7}{|c|}{12} \\
\hline Curt. value as \% & 22.3 & 17.4 & 13.1 & 9.6 & 6.7 & 4.4 & 2.8 \\
\hline Curt. mag. as \% & 25.8 & 20.6 & 16.1 & 12.2 & 8.9 & 6.2 & 4.2 \\
\hline
\end{tabular}

Table 2: 2014 wind data scaled to $37 \%$ average penetration

\begin{tabular}{|c|c|c|c|c|c|c|c|}
\hline SNSP limit & $\mathbf{5 0 \%}$ & $\mathbf{5 5 \%}$ & $\mathbf{6 0 \%}$ & $\mathbf{6 5 \%}$ & $\mathbf{7 0 \%}$ & $\mathbf{7 5 \%}$ & $\mathbf{8 0 \%}$ \\
\hline Hours of curt. & 3599 & 3214 & 2839 & 2481 & 2153 & 1833 & 1512 \\
\hline Curt. energy (GWh) & 3931 & 3204 & 2556 & 1985 & 1487 & 1058 & 696 \\
\hline Value, curt. energy (£m) & 150 & 121 & 95 & 73 & 54 & 37 & 24 \\
\hline Value, all wind (£m) & \multicolumn{7}{|c|}{577.7} \\
\hline Mag., all wind (GWh) & \multicolumn{7}{|c|}{13756.7} \\
\hline Curt. value as \% & 26.0 & 20.9 & 16.4 & 12.6 & 9.3 & 6.4 & 4.2 \\
\hline Curt. mag. as \% & 28.6 & 23.3 & 18.6 & 14.4 & 10.8 & 7.7 & 5.1 \\
\hline
\end{tabular}

The overall magnitude of curtailment seen across both years was different due to the higher demand in 2014 compared to 2013. However, the timing and relative spread of curtailment was very similar in both years, as can be seen in Figure 2, with curtailment peaks roughly coinciding with periods of low demand, high import, and high wind generation. This echoes the results found by Devlin et al. in [6].

Curtailment did not drop linearly as the SNSP limit was raised, but rather followed the principle of diminishing 


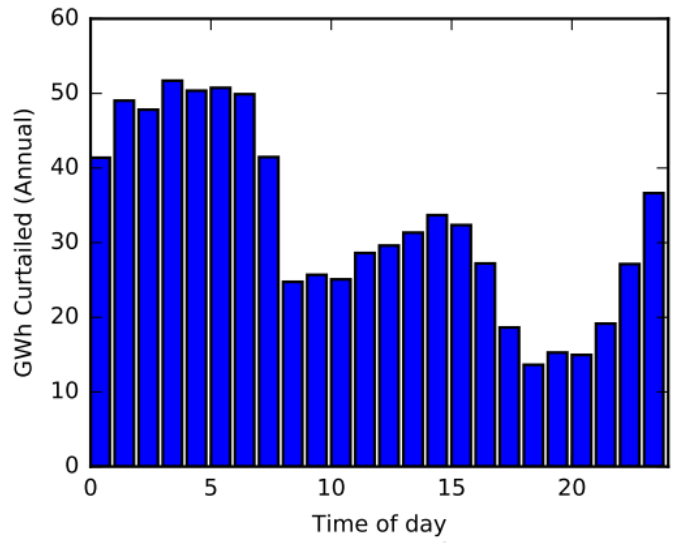

a

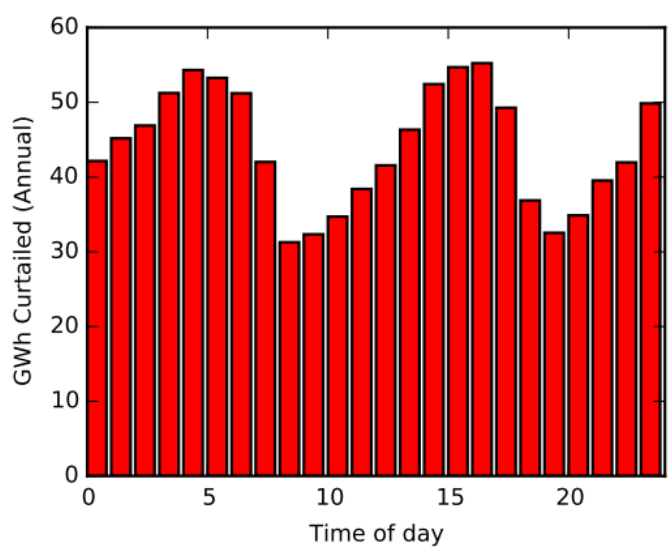

$\mathrm{b}$

Figure 2: Annual energy curtailed by hour of day for (a) scaled 2013 data and $(b)$ scaled 2014 data. Wind energy penetration $=37 \%$, SNSP $=75 \%$

returns, as can be seen in Figure 3, which shows the reduction in curtailment resulting from an increase in the SNSP limit compared to the $50 \%$ baseline. It would not be possible to totally eliminate curtailment, as wind penetration potential was occasionally seen to go above $100 \%$ of demand.

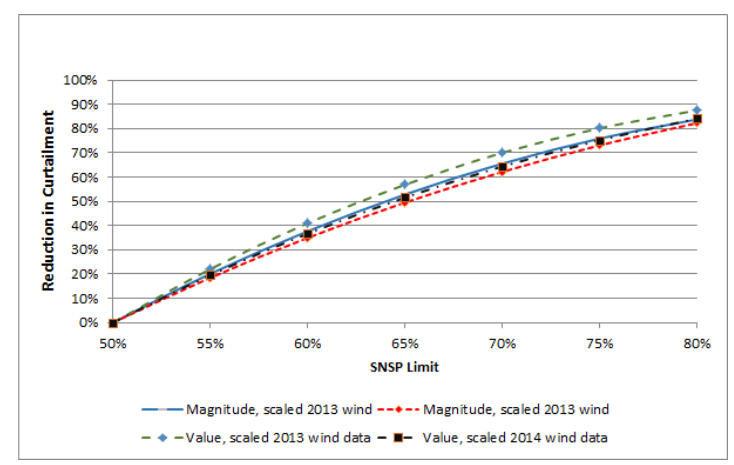

Figure 3: Change in curtailment with increasing SNSP relative to $50 \%$

As can be seen from both Tables 1 and 2, curtailment consistently dropped as the SNSP limit was increased, as might be expected. The value of curtailed energy as a proportion of the value of all wind energy was consistently lower than the magnitude of curtailed energy as a proportion of all wind energy. This is because curtailment peaks during times when the SMP is low, meaning that the 'lost' energy is worth less than it might otherwise be. If the 5\% curtailment limit stated in [11] were taken to mean $5 \%$ curtailment by economic value (f) rather than by magnitude (MWh), then curtailment levels of $5-8 \%$ by magnitude might be considered acceptable without undermining the economic case for wind generation. 
Due to the fact that HVDC interconnection is non-synchronous, increased interconnection could actually increase curtailment on the Irish power system, particularly during periods of high import. This is due to the competition between import $I$ and wind generation $W$, as may be seen from the numerator of eqn. 1 for a particular SNSP. Ireland tends to import more power than it exports due to the lower electricity prices on the larger British power system. Figure 4 shows an approximation of curtailment by time of day using the scaled 2014 data. The dashed line shows the curve of curtailment with active interconnection while the solid line shows the curtailment curve for the same time period but with interconnection eliminated from the system. While this analysis does not take into account the effect that the lack of interconnection would have on system operation, it does give an approximation of the amount of additional curtailment of wind that might be expected from importing energy along HVDC interconnectors. Without an increase in SNSP or limits on interconnector import during high-wind periods, interconnection could not be relied upon as a means to reduce curtailment.

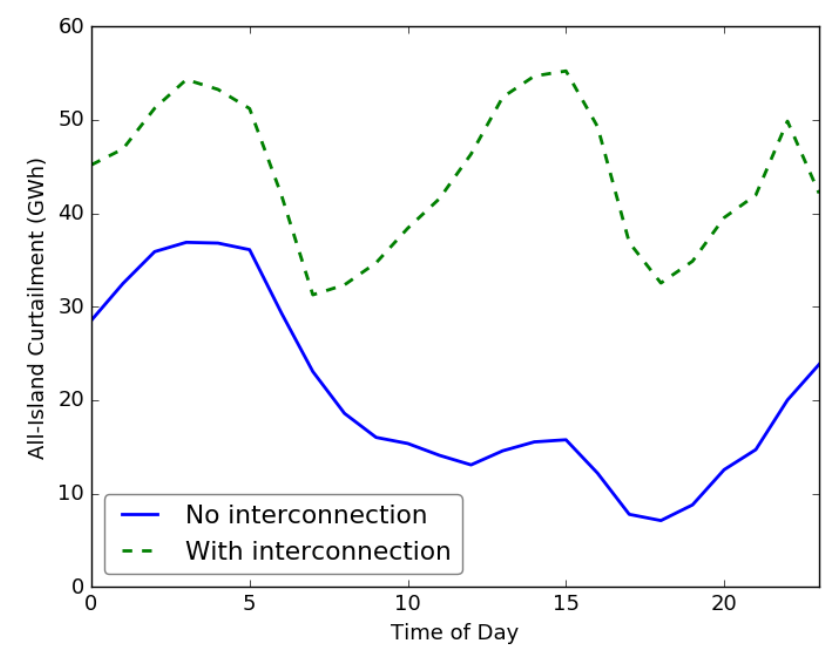

Figure 4: Annual curtailment by hour of day with and without interconnection. Scaled 2014 data for $37 \%$ wind energy penetration

\section{Mitigation with water DSM}

Without changing the SNSP limit on the Irish power system, it would be possible to increase the non-curtailed magnitude of wind generation by increasing the demand during periods of curtailment. Equation 1 indicates that, with an SNSP limit of $60 \%$, every $1 \mathrm{MW}$ of added load would allow $600 \mathrm{~kW}$ of otherwise curtailed wind power onto the power system (assuming no change in interconnector flows).

In the Irish Single Electricity Market (SEM), SMP was based on the operating cost of the single most expensive 
in-merit generator. Wind power was considered to have zero operating cost and is thus 'price-taking'. In theory, high penetrations of wind generation displace low-merit generation, thus reducing system price. In a system with high penetrations of wind generation, optimising load based on an SMP RTP tariff should encourage demand during high-wind periods and thus have an effect on curtailment. The SEM was replaced in October 2018 with the I-SEM (Integrated Single Electricity Market) which is composed of two ahead-of-time energy markets, a balancing market, two markets for financial instruments, and a market for capacity, all of which operate independently [19]. However, use of data from the former SEM allows comparisons to be made with historical data.

One flexible load suited to DSM is municipal water supply, specifically clean water pumping. In a power system with high wind power penetration, curtailment mitigation could be regarded as a desirable ancillary service, and DSM of water supply has been shown to be a viable means of supplying ancillary services to power systems, particularly reserve [20].

In water supply systems, catchment areas (frequently lakes or reservoirs in mountainous regions) supply water which is treated and then pumped to service reservoirs near population centres. These provide consumers with water either via hydrostatic head or top-up pumps. Water supply systems employing service reservoirs have an inherent flexibility in electricity demand as pumping is not time-critical: provided that a minimum level of water is maintained in these service reservoirs, the operation of the supply pumps is otherwise flexible (depending on supply from catchment areas and water treatment facilities). By scheduling pumping to coincide as much as possible with periods of wind curtailment, it should be possible to reduce the amount of curtailment seen on the power system.

\subsection{Case Study - Belfast}

Average clean water consumption per person in Northern Ireland (NI) is 360 1/day [24], and hence Belfast requires $180 \mathrm{Ml} /$ day for the population of 500,000.

Belfasts water supply system is outlined in Figure 5. The main sources of supply are the Silent Valley reservoir in the Mourne Mountains to the south, and Lough Neagh to the west. The Silent Valley reservoir provides a head of 90 $\mathrm{m}$, while Lough Neagh has a head of $-76 \mathrm{~m}$. Hence more pumping capacity and energy is required to supply a given volume from Lough Neagh compared with the Silent Valley. The favoured Silent Valley supply is conserved over time by limiting its output to $130 \mathrm{Ml} / \mathrm{day}$. The main parameters of the Belfast water supply system are given in Table 3. The average electrical load is $2.3 \mathrm{MW}$ not enough to have a significant effect on system marginal price, but large 
Table 3: Belfast's main sources of water [27] [28]

\begin{tabular}{|c|c|c|}
\hline & Silent Valley & Lough Neagh \\
\hline Pipe length & $56 \mathrm{~km}$ & $18 \mathrm{~km}$ \\
\hline $\begin{array}{c}\text { Service reservoir } \\
\text { capacity (approx. }^{*} \text { ) }\end{array}$ & $150 \mathrm{Ml}$ & $200 \mathrm{Ml}$ \\
\hline Total head gain & $-76 \mathrm{~m}$ & $90 \mathrm{~m}$ \\
\hline Max pumped flow & $130 \mathrm{Ml} /$ day & $180 \mathrm{Ml} /$ day \\
\hline Pump power & $1.2 \mathrm{MW}$ & $3 \mathrm{MW}$ \\
\hline
\end{tabular}

${ }^{*}$ Approximated from available data

enough to reduce curtailment if applied in a timely fashion. With a peak demand of 4.3 MW, Belfasts water supply could represent up to $2.4 \%$ of total Belfast load, which can be as low as $180 \mathrm{MW}$ at night. It is representative of water supply systems on the island of Ireland and many other countries.

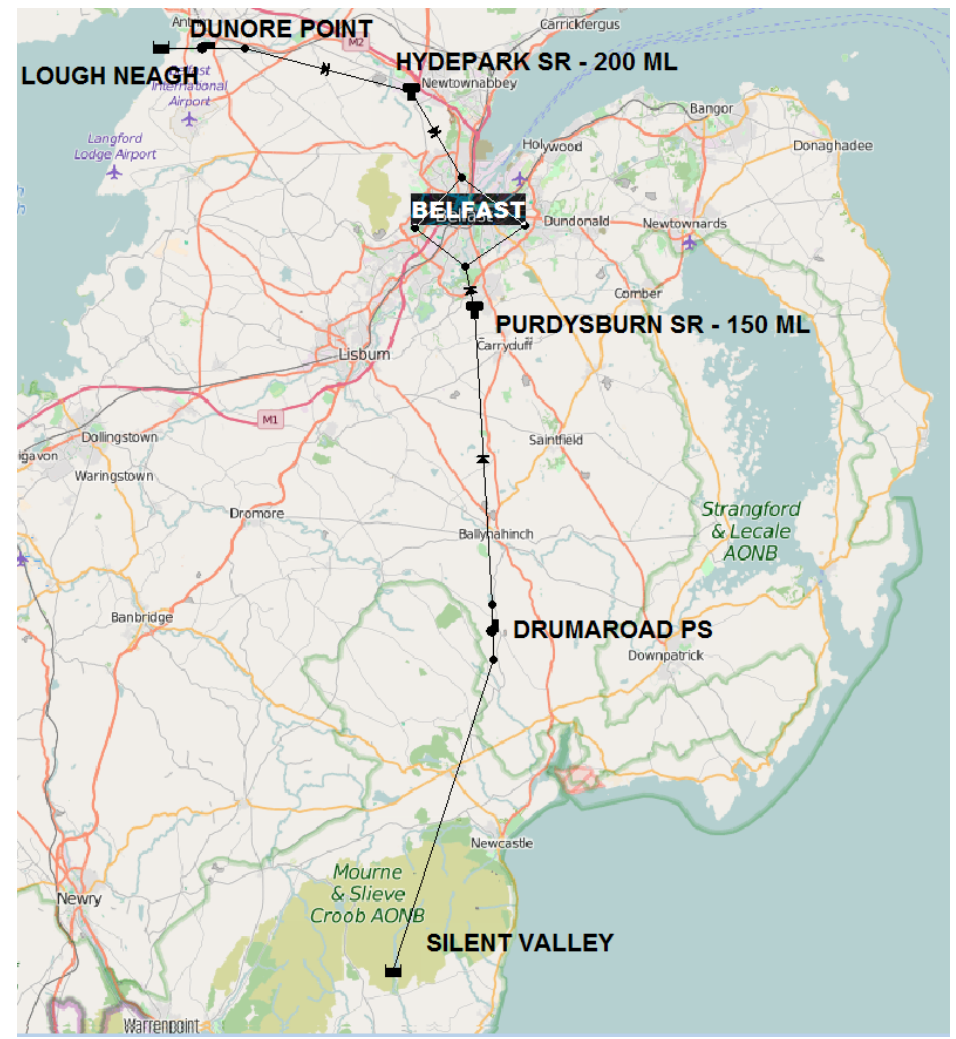

Figure 5: EPANET diagram of the Belfast water supply system model

The two large catchment areas supply service reservoirs closer to Belfast via treatment plants. These plants are best operated at constant load. The service reservoir capacities are generally sufficient for a days supply, and pump capacity is such that it is possible to control water storage between $10 \%$ and $100 \%$ of capacity. Hence pump operation can be decoupled from water supply to a certain extent. The resulting flexibility has encouraged Northern Ireland Water 
(NIW) to use cheap night-time electricity to fill the service reservoirs, which then discharge the bulk of the stored water during the day. However, the emergence of significant renewable generation has disrupted the economic basis for this simple regime, due to periods of cheap electricity occurring at various times when wind generation becomes available. The authors previously explored the potential to schedule water pumping more economically based on a real-time tariff [26]. The focus here is related but different: to minimise wind curtailment, again exploiting the flexibility of water pumping load.

EPANET, a program developed by the US Environmental Protection Agency [24], was used to model the Belfast water supply system [25]. The water demand is represented by four interconnected nodes. Head loss in all pipework is modelled in EPANET by the Hazen-Williams formula:

$$
h_{f}=\frac{10.67 Q^{1.85}}{C^{1.85} d^{4.87}}
$$

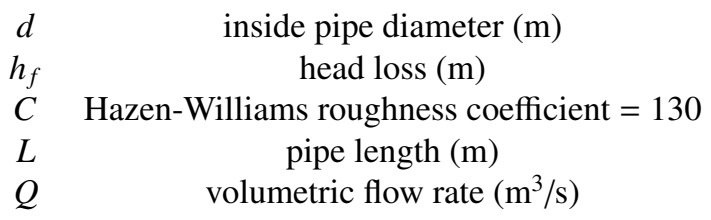

Pump power was calculated from pump flow rates and head. The model assumed fixed-speed pumps that were either on at full power, or off. These are being replaced by variable-speed pumps, which would tend to ease the pump scheduling task. Pump scheduling was optimised one day at a time. To avoid water shortages, service reservoir levels at the end of each day were restored to at least $90 \%$ of their levels at the start of the study period.

Daily pump schedules were obtained using a genetic algorithm (GA). Each pump schedule was represented by a 48-bit string representing pump on or off status over 48 half-hour periods. Each proposed schedule was simulated by EPANET, which returned a cost based on pump energies and related electricity costs. Hydraulically infeasible schedules were penalised; more than four off/on pump operations were also penalised. 50 generations were examined, with a population of $200.100 \%$ crossover was used, with a mutation rate of $3 \%$. These GA parameters were obtained by trial and error. The integration of the GA with EPANET was facilitated by the Python programming language.

The best solution satisfying the constraints determined the initial state for the next day. 
The water supply system was first optimised based on a traditional ToU multi-rate tariff (T1), as is the case currently in Northern Ireland. This constituted the base case. The tariff is not directly related to market operation, but varies by time of day, giving lower rates at night and off-peak. The power consumption over the year of interest was then subtracted from the system load curve. The water system was then re-optimised on the basis of a number of scenarios (see Figure 7) and the power consumption added back to the system load. It was then possible to re-calculate wind penetration figures and curtailment as shown in Section 2. This highlighted the changes that optimisation for the different scenarios had on system-wide curtailment. All scenarios had average power consumptions within $2 \%$ of each other. The years 2013 and 2014 were both analysed. Water demand data were supplied by NIW [29].

The scenarios investigated can be seen in Table 4. Two scenarios (EP2 and Max Wind) used 'perfect foresight' data, which would in reality not be available until after the period in question. These were included as they represent best possible cases for minimising price or maximising wind power utilisation, respectively. In reality, optimisation would have to be carried out based on a forecast of wind generation or SMP. Forecasts of price (EA1) and wind power (Two Day Wind Forecast) were available to market participants in the SEM, and these were used as the basis of two further scenarios here as they represent a realistic means by which load could be scheduled ahead of time.

Table 4: Scenarios Investigated

\begin{tabular}{|c|l|}
\hline Scenario & Description \\
\hline Base case (Multirate/T1) & $\begin{array}{l}\text { Minimise cost based on multirate tariff (4 tier); } \\
\text { lower at night and off-peak }\end{array}$ \\
\hline EP2 & $\begin{array}{l}\text { Minimise cost based on Ex-Post 2 SMP } \\
\text { (known 4 days after trading date in SEM) }\end{array}$ \\
\hline EA1 & $\begin{array}{l}\text { Minimise cost based on Ex-Ante 1 SMP, } \\
\text { forecast made publicly available 1 day before trading date }\end{array}$ \\
\hline Max Wind & $\begin{array}{l}\text { Demand scheduled to maximise uptake usage of wind power, } \\
\text { based on perfect foresight of wind penetration }\end{array}$ \\
\hline Forecast Wind & $\begin{array}{l}\text { Demand scheduled to maximise uptake usage of wind power, } \\
\text { based on two-day wind forecast provided by SEM-O }\end{array}$ \\
\hline
\end{tabular}




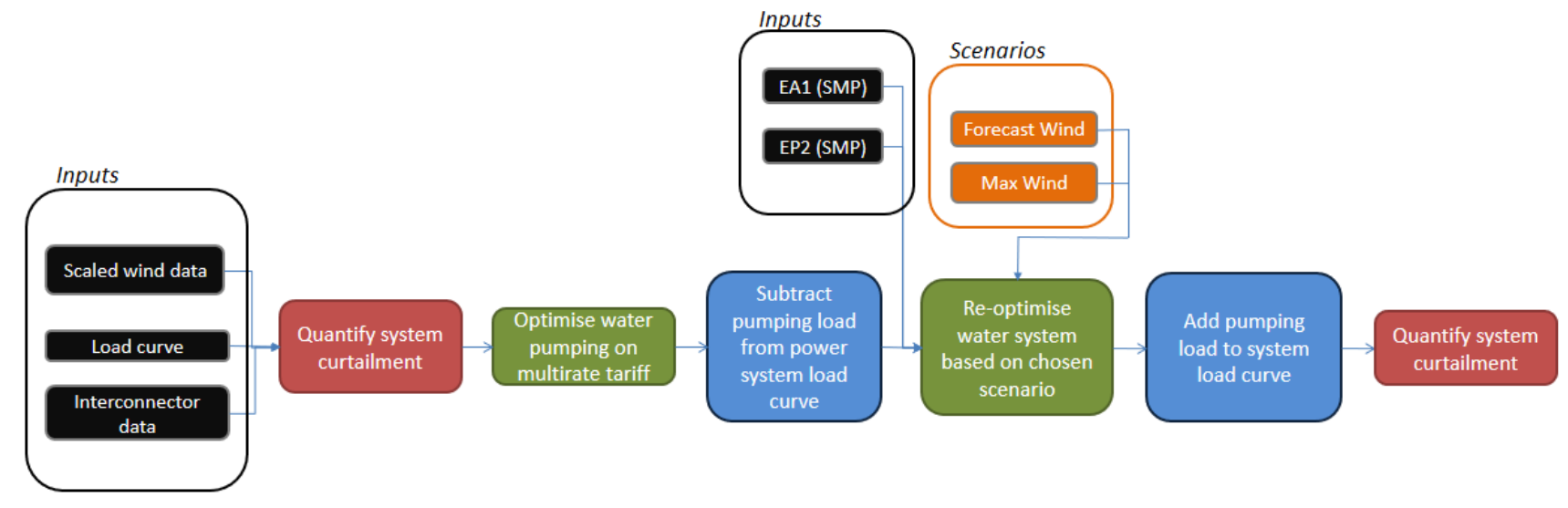

Figure 6: Flowchart outlining methodology

\subsection{Case Study Results}

The objective in the first two scenarios, EP2 and EA1, was to minimise the cost of supplying the water pumping load. The Max Wind and Forecast Wind scenarios focussed on alignment of the pumping load with the actual wind profile and the profile forecast two days in advance. In all cases the values and magnitudes of curtailment are subtracted from the values obtained for the base case, which was a supply cost minimisation based on the traditional multi-rate T1 tariff.

The reductions in curtailment values for EP2 and EA1 are shown in Figure 7, while the reductions in curtailment magnitudes are shown in Figure 8, both for increasing SNSP. The reductions that might be achieved in reality lie between the two graphs, given that the pump schedules would benefit from forecast updates that improve on EA1, while lacking the accuracy of EP2. Curtailment value and magnitude reductions tend to increase with SNSP, reflecting more generous allowances for wind power penetration.

The corresponding results for Max Wind and Forecast Wind are also shown in Figures 7 and 8. Again, realistic curtailment reductions are likely to lie between the two forecasting extremes. The reductions are largely constant over the realistic SNSP range, viz. $60 \%-75 \%$.

It is clear from Figures 7 and 8 that greater curtailment reductions, whether by value or magnitude, are achievable with the wind forecast optimisations than with SMP-based EP2 and EA1. This is to be expected, as the pumping load is thereby aligned with wind generation directly. By contrast, SMP-based optimisation (EP2 and EA1) are successful 
only to the extent that SMP is reduced by wind generation. In reality, system demand is the main determinant of SMP.

However, SMP-based optimisation minimises the cost of pumping load supply. This may be seen from the cost of pumping load supply over year 2014 with the base case and the four scenarios of interest (Table 5):

Table 5: Cost of pumping. All costs are retrospective

\begin{tabular}{|c|c|}
\hline $\begin{array}{c}\text { Case } \\
\text { T1 (base case) }\end{array}$ & $\begin{array}{c}\text { Cost } \\
£ 792 \mathrm{k}\end{array}$ \\
\hline EP2 & $£ 698 \mathrm{k}$ \\
\hline EA1 & $£ 763 \mathrm{k}$ \\
\hline Max Wind & $£ 776 \mathrm{k}$ \\
\hline Forecast Wind & $£ 803 \mathrm{k}$ \\
\hline
\end{tabular}

It is seen that the savings relative to the base case are greatest for EP2, followed by EA1. The lower curtailment values achieved with Max Wind and Forecast Wind come at a cost. A compromise solution that retains the economic benefits of SMP-based optimisation, while switching pumping load to forecast curtailment periods, is presented in Section 4 below.

Figure 9 shows the power consumption by time of day for selected scenarios of the 2014-based data across the full year. Also shown is curtailment at the $75 \%$ SNSP setting for the same year. The curtailment curve, as previously mentioned, is heavily affected by interconnector flows for the year in question, accounting for the peak seen during the middle of the afternoon. Both wind-based optimisations gave an aggregated power consumption curve which closely followed the equivalent curve for curtailment. EP2- and EA1-based operation were very similar to each other. T1-based operation tracked curtailment more closely than EP2, despite having no connection with market operation. In the SEM, the EP2 price took into account network constraints which are not considered at EA1. It is likely that these constraints mask the effect of wind generation on the electricity price.

It should be noted that the results seen here are dependent on the multirate optimisation giving a valid approximation of how water pumping systems are currently run. In reality, formal optimisation such as this is not always carried out on pumping systems, as they frequently lack the capability of being programmed or controlled remotely. In the case where a system does not already follow a rigorous price-based optimisation, a switch to such a regime would likely give better results than those seen here. The forecast data used here were also those available one day in advance - in reality, more accurate forecasts would be available closer to the time, which could then be used to update the optimisation. 
The scenarios examined here consider a much greater wind penetration - $37 \%$ - than in the original data, e.g. $20 \%$ in 2014. It is to be expected that the higher levels of wind in the scenarios would depress SMP for given fuel (mainly gas) prices. On the other hand, SMP at times of light wind would remain much the same. The overall effect would be to increase the incentive to shift load to periods of low SMP. Hence the results presented above probably understate the advantages of load scheduling based on SMP. It should also be noted that the development of off-shore wind on Ireland's east coast will redress the current predominance of on-shore wind power in the west, aiding diversity and improving forecasts.

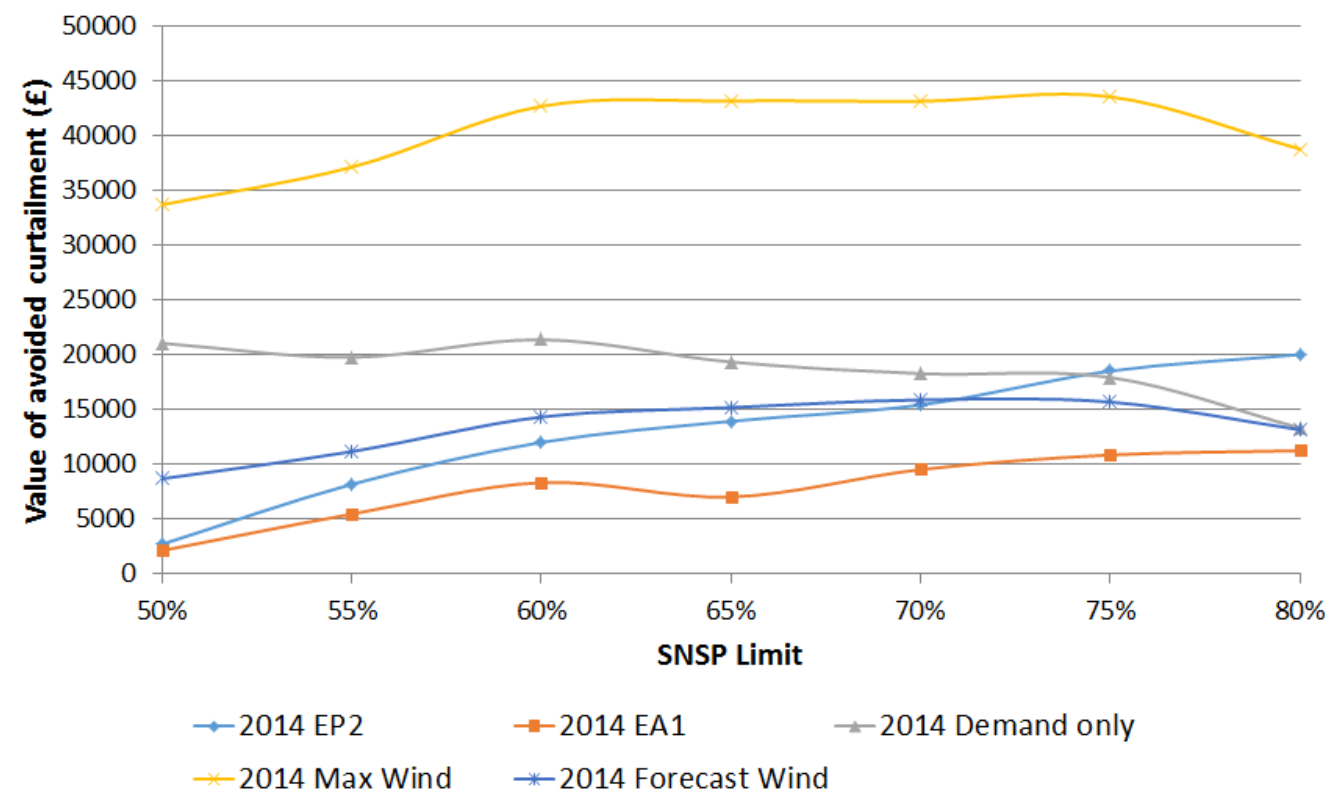

Figure 7: All 2014 scenarios, economic value of avoided curtailment v. SNSP (positive $=$ reduction) 


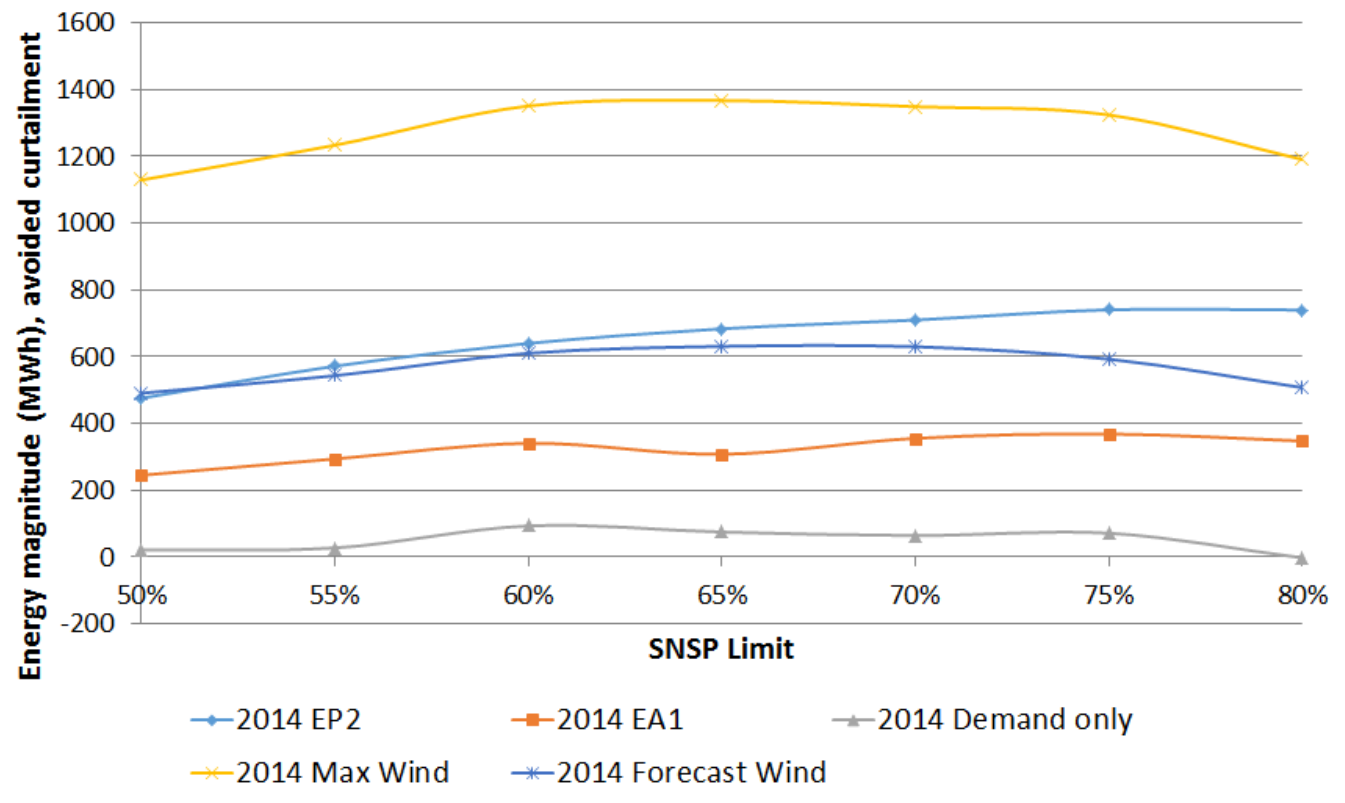

Figure 8: All 2014 scenarios, energy magnitude of avoided curtailment v. SNSP (positive = reduction) 


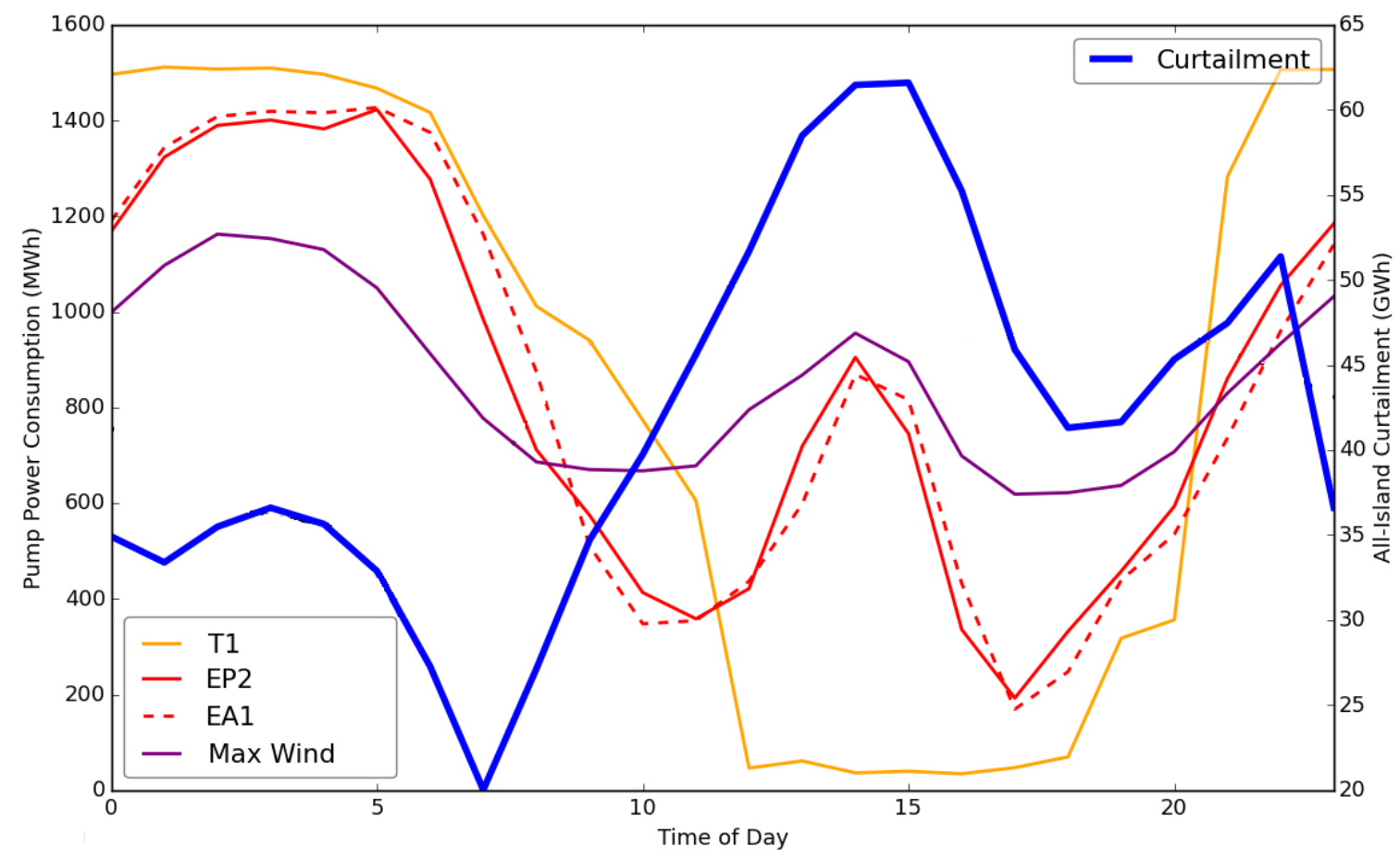

Figure 9: Pump energy consumption and curtailment by hour of day. Scaled 2014 data

\section{Augmented SMP Scheduling}

\subsection{Incentive Scheme to Reduce Curtailment}

The SMP based optimisations in Section 3 (EP2 and EA1) scheduled load purely on the basis of market price, without reference to curtailment of wind. As can be seen in the results found above, the relationship between SMP and curtailment is not strong enough for SMP-based load scheduling to minimise wind curtailment.

SMP represents the cost of adding one additional megawatt of generation to the power system - this is what makes it a 'marginal' price.

During period $i$, one additional MW of load would cost $\left(\mathrm{C}_{i}\right)$ :

$$
C_{i}=\mathrm{SMP}_{i} \times(1 \mathrm{MW})
$$

From Equation 1, when curtailment is occurring, for a given interconnector flow, increasing demand by 1 MW allows more wind energy $(\Delta W)$ onto the system:

$$
\Delta W=\mathrm{SNSP} \times(1 \mathrm{MW})
$$


Wind generation is 'price-taking', meaning that it does not set SMP as it has no intrinsic marginal cost. In a curtailment scenario, increasing demand will not cause a corresponding increase in 'price-setting' generation due to the increase in wind generation seen in Equation 5. Therefore, under these circumstances, the true economic cost of one extra MW of load is not the SMP, but rather the SMP minus the value of the wind energy that would otherwise be lost due to curtailment:

$$
C_{i}=\mathrm{SMP}_{i}(1-\mathrm{SNSP})
$$

The higher the SNSP value, the more that additional demand could actually offset curtailment.

Equation 6 could be used to produce an 'augmented' SMP curve. Figure 10 shows the EP2 SMP curve for a day in the 2014-based data from Section 3 alongside the 'augmented' SMP curve from the same day. The divergence of the 'augmented' curve from the EP2 data represents periods during which curtailment is occurring. The area between the curves is the value of the curtailment that one additional MW of load would offset.

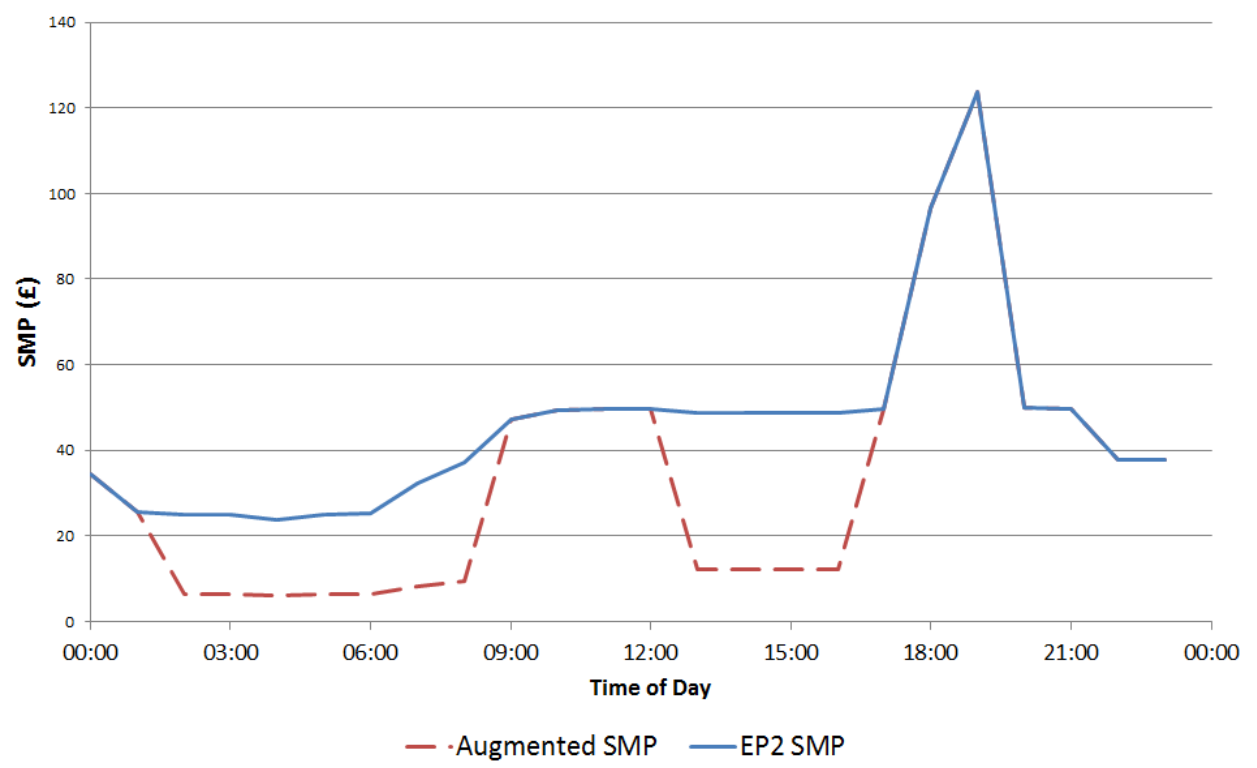

Figure 10: Augmented and EP2 SMP, 21 February 2014. SNSP =75\%

A version of the curve in Figure 10 could be used as the price signal for optimisation of a flexible load. During periods of no curtailment it would be the same as the SMP curve, but if curtailment were imminent, or actually occurring the price would be reduced, which would incentivise an increase in load. 


\subsection{Results for Augmented SMP}

In order to investigate this, the EP2 SMP optimisation of water pumping in Section 3 was modified to schedule on the basis of this 'augmented' SMP curve. The optimisation was carried out at a SNSP of 75\%. A summary of the results, along with a comparison with no optimisation and EA1 and EP2 optimisation, can be seen in Table 6 below. Scheduling on the basis of the 'augmented' SMP resulted in a significant increase in both the magnitude and value of curtailment avoided in both years. The 2014 data gave $1.3 \mathrm{GWh}$ of avoided curtailment for an average electrical demand of 2.3 MW and a peak demand of 4.3 MW. The water system modelled here represents approximately one twelfth of overall water demand. Scaling the results seen here accordingly suggest that reduction in curtailment in the region of $15 \mathrm{GWh}$ per year could be realised with water pumping optimisation alone.This would probably be a little less due to the inherent diminishing returns and the varying levels of demand flexibility within the water supply system.

Table 6: Augmented EP2 SMP v. standard SMP, 2013 and 2014 data, 75\% SNSP

\begin{tabular}{|c|c|c|}
\hline Scenario & Change in Curtailment Magnitude (MWh) & Change in Curtailment Value (£) \\
\hline \multicolumn{2}{|c|}{$\mathbf{2 0 1 3}$} \\
\hline EA1 & -228 & -6109 \\
\hline EP2 & -445 & -10217 \\
\hline Augmented EP2 & -909 & -44438 \\
\hline \multicolumn{2}{|c|}{$\mathbf{2 0 1 4}$} \\
\hline EA1 & -369 & -10791 \\
\hline EP2 & -741 & -18474 \\
\hline Augmented EP2 & -1325 & -44245 \\
\hline
\end{tabular}

Figure 11 shows the power consumption by time of day for both scenarios, for both years. In both cases, the pump power consumption more closely followed curtailment when scheduled on the basis of the 'augmented' SMP than on the basis of SMP alone. Pumping costs for 2013 and 2014 were $£ 611 \mathrm{k}$ and $£ 685 \mathrm{k}$ respectively, lower than all other optimisations.

Optimising on the basis of this 'augmented' SMP would allow a more economically justified cost to be applied to flexible load. There are, however, some disadvantages to this approach - it is dependent on foresight of both market price and curtailment, and any inaccuracy in the forecasting of either would reduce the effect on curtailment. However, if the price signal provided to the load were to be updated as new data on curtailment and price became available, these uncertainties would be largely overcome. This would, in effect, be a mixture of the purely market-driven approach discussed in Section 3, and explicit system operator intervention in DSM. The operator would still not have direct control over load, but would be able to provide an up-to-date incentive for load to be increased during periods of 


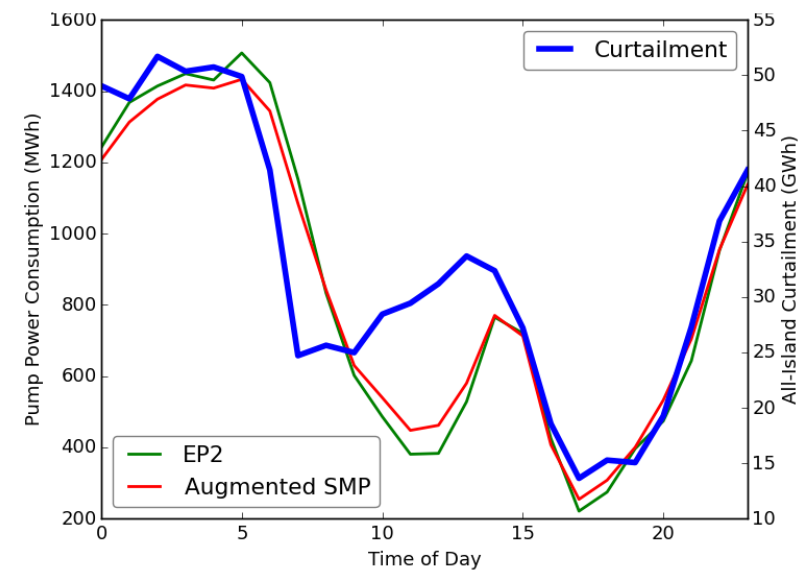

a

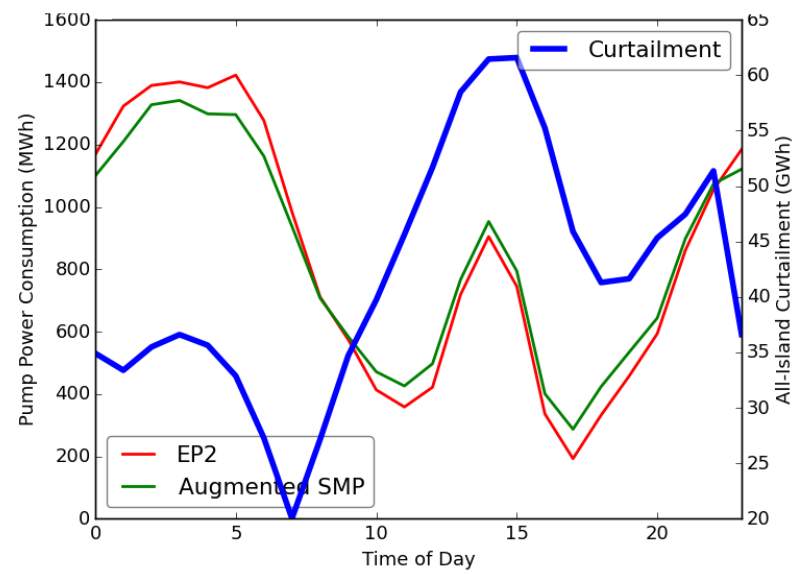

b

Figure 11: Augmented SMP v. EP2, pump energy consumption and curtailment (75\% SNSP) by time of day, (a) 2013- and (b) 2014-based data

curtailment.

Tariff design would be critical with this approach - if the additional wind generation was rendered 'free', as seen here, then it may not be seen as beneficial to suppliers as there is no cost difference between this approach and allowing curtailment to take place. A possible solution might be to drop use of system charges for flexible loads at times of potential curtailment. It could be argued that, by helping to reduce or avoid curtailment, such loads are providing an ancillary service, and should be charged SMP only. Curtailment tends to occur at times when the system is lightly loaded, further justifying this approach. The use of system charges would be restored at other times. However, if a small cost were ascribed to the additional wind (some fraction of SMP perhaps), then customers would still pay for the additional wind being allowed on the system while also saving money compared to paying the full SMP. Since the increased load during periods of curtailment would in all probability result in load being reduced during other times, it is likely the overall reduced need for 'price-setting' generation would reduce system costs.

\subsection{Significance of Augmented Approach to Water Pumping}

Water pumping is an excellent candidate for early adoption of DSM aimed at reducing wind energy curtailment. The industry has significant scale, comprising an estimated $28 \mathrm{MW}$ of pumping plant in Ireland. Much of this capacity is remotely controlled already, typically taking advantage of traditional time-of-use tariffs. Hence the communications infrastructure needed to effect control based on real-time prices is largely in place. Extending this capability is cheap relative to the ratings of individual pumps. The water industry also has the operational expertise to implement pump 
scheduling based on the augmented SMP approach advocated here.

An additional advantage of water pumping load is that it is well distributed, with service reservoirs near most towns. Hence there is scope to incentivise pumping load to alleviate network constraints arising from wind generation in the locality.

There will be some emission $\left(\mathrm{CO}_{2}\right)$ reductions from transfer of fossil-fuelled to wind generation during curtailment episodes. However, the real significance is that, while augmented SMP scheduling of water pumping load can reduce present wind curtailment, it encourages future wind power development. The base case is the 2020 scenario with a $37 \%$ wind contribution and water pumping load scheduled to take advantage of the Time of Use (ToU) tariff. Applying both the 2013 and 2014 derived wind generation data, the resulting wind curtailment is 922 GWh per annum. Water pump scheduling based on augmented SMP was applied to the same data, with increasing wind capacity. It was found that the same level of wind curtailment was reached when the wind capacity was $1.14 \mathrm{MW}$ greater. Given that the Belfast system represents around one twelfth of the Irish system, it can be assumed that all-island application of augmented SMP to water pumping load would allow approximately an extra 13.7 MW of wind capacity to be deployed for the same curtailment as ToU-based scheduling. Note that the extra wind capacity is about half of the water pump rating. While we have focused here on water pumping load, similar arguments can be made for commercial refrigeration plant and other flexible loads.

\section{Conclusions}

Wind power curtailment on the Irish SEM was significant and is likely to remain so in ISEM, even with an increase of the SNSP limit. If the 5\% of wind energy curtailed described in [11] is taken as a hard limit then it will almost certainly be necessary to implement DSM schemes (and possibly storage) when the power system is nearing its wind penetration targets. If the 5\% limit is taken as an economic rather than a physical limit then this would give the system operator greater leeway, as $5 \%$ of wind energy curtailed by value corresponds to approximately $8 \%$ curtailed by magnitude.

HVDC interconnection cannot necessarily be relied on to reduce curtailment, as its non-synchronous nature means that it must compete with wind generation when both import and wind generation are significant or face curtailment itself. Currently, Ireland only has interconnection with the British system. The argument has been made that import 
is unlikely during high wind events due to electricity prices in Ireland being driven down by wind generation, thus making Irish electricity appealing to consumers in Britain. It is worth noting, however, that high wind events that occur in Ireland usually occur concurrently in Britain, which also has significant (and increasing) wind generation, reducing British electricity prices. The economies of scale inherent in the larger British system also make it less likely that electricity export can be relied upon to mitigate curtailment.

DSM has the potential to mitigate curtailment without explicit operator intervention, provided that the load in question is sufficiently flexible. One method of achieving this effect is by scheduling load on the basis of the penetration of wind generation by providing a tariff proportional to this variable. Since loads such as municipal water supply require scheduling in advance, giving sufficient and accurate notice of changes in price would result in the maximum possible mitigating effect on curtailment. Forecasting accuracy would be key, and a combination of rolling optimisation and price updates could improve the results from the power system perspective. In order to entice users to take part in such a scheme, it might be beneficial for the customer to be offered a firm price one day in advance, with the risk and uncertainty of forecasting being carried by the supplier.

Optimising flexible load on the basis of SMP did produce some mitigation of curtailment compared to multirate optimisation in this investigation, but this was entirely dependent on accurate pricing information being available ahead of time. Such a regime may, however, be beneficial compared to an unoptimised system, and is also likely to present the highest possible cost savings to the consumer [26]. The relationship between SMP and wind energy was not sufficient in the SEM to advocate SMP-based optimisation as an effective means to mitigate curtailment compared to optimisation based on a multirate tariff. This could be compensated for by providing an augmented version of an SMP-based tariff which takes into account the economic benefit of avoided curtailment and thus provides a direct financial incentive to consume during periods when curtailment is occurring. Such a tariff would also serve to flatten the load curve (especially when compared to the wind penetration-based tariff) as it would penalise consumption during peak times.

The augmented SMP approach applied to water pumping load proved to be a highly effective way of reducing curtailment, while maintaining most of the economic benefit of basic SMP scheduling. Curtailment was reduced by an additional (approximate) $500 \mathrm{MWh}$ with augmented SMP scheduling. The main advantage of this is that it allows additional wind capacity to be installed for the same level of curtailment as in an un-optimised load scenario, which would replace fossil-fuelled generation. The extra wind capacity for augmented SMP optimisation compared to ToUbased optimisation of the entire Irish water supply system is estimated to reduce $\mathrm{CO}_{2}$ emissions on the Irish power 
system by 21,500 tonnes per annum. Other sectors provide similar DSM opportunities, such as refrigerated food storage facilities, However, as the magnitude of DSM increases to include these possibilities, the effect of DSM on the system marginal price should be included in the analysis.

\section{Acknowledgement}

The authors would like to thank Northern Ireland Water for the provision of data and access to system information, and the NI Department of Employment and Learning for project funding.

\section{References}

[1] EWEA. Wind in power: 2013 European statistics. Brussels, Belgium. 2014. Cited January 2019. [online] http://www . ewea. org/ fileadmin/files/library/publications/statistics/EWEA_Annual_Statistics_2013.pdf

[2] SEAI. Wind Energy, https://www. seai.ie/sustainable-solutions/renewable-energy/wind-energy/, 2019 [accessed January 2019]

[3] McGarrigle, EV, Deane, JP, Leahy, PG. How much wind power will be curtailed on the 2020 Irish power system? Renew. Energ.. 2013; 55:544-553

[4] Eirgrid. Smart Grid Dashboard, smartgriddashboard.eirgrid.com [Accessed January 2019]

[5] Kernan, R et al. The Effect of Wind Generation on Wholesale Electricity Prices in Ireland. Proceedings of the 16th Wind Integration Workshop, Berlin, 2017.

[6] Devlin, J et al. System flexibility provision using short term grid scale storage. IET Proc. Gener. Trans. Distr. 2016;10(3):697-703.

[7] Martin-Almenta, M. et al. Analysis of wind curtailment and constraint at a nodal level. IEEE Trans. Sus. Energy. 2017:8(2);488-95.

[8] EirGrid. DS3 programme operational capability outlook 2016. Tech. report 2016.

[9] EirGrid and SONI. Annual renewable energy constraint and curtailment report 2015. Tech. report 2016.

[10] McGarrigle, EV, Leahy, PG. Cost savings from relaxation of operational constraints on a power system with high wind penetration. IEEE Trans. Sus. Energy. 2015;6(3):881-88.

[11] Eirgrid and SONI. Volume calculation methodology and portfolio scenarios. Tech. report 2016.

[12] Adika, CO, Wang, L. Autonomous appliance scheduling for household energy management. IEEE Trans. Smart Grid 2014;5(2):67382.

[13] Pourmousavi, SA et al. Real-time demand response through aggregate electric water heaters for load shifting and balancing wind generation. IEEE Trans. Smart Grid 2014;5(2):769-77.

[14] Van Staden, AJ et al. A model predictive control strategy for load shifting in a water pumping scheme with maximum demand charges. Appl. Energy 2011;88:4785-94.

[15] Schweppe, FC et al. Homeostatic utility control. IEEE Trans. Power App. and Sys.1980;99(3):1151-63.

[16] Kernan, R. Flexible operation of municipal water supply system to facilitate variable generation potential. Doctoral dissertation, Queens University Belfast, 2017.

[17] Fox, B et al. Wind power integration: operational and connection aspects. Second edition. IET, London.

[18] Touhy, A, OMalley, M. Impact of pumped storage on power systems with increasing wind penetration. IEEE Power \& Energy Society General Meeting 2009. 
[19] Single Electricity Market Operator. Markets, https://www.sem-o.com/markets/ [Accessed January 2019]

[20] Menke, R et al. Demonstrating demand response from water distribution through pump scheduling. Appl. Energy 2016;170:377-87.

[21] Lau, ET et al. Carbon savings in the UK demand response programmes. Appl. Energy 2015;159:478-89

[22] Albadi, MH, El-Saadany, EF. A summary of demand response in electricity markets. Elec. Pow. Sys. Res. 2008;78(11);1986-96.

[23] Ma, O et al. Demand response for ancillary services. IEEE Trans. Smart Grid 2013;4(4):1988-95.

[24] NI Water. Annual Report 2014-15, https://www.niwater.com/sitefiles/resources/pdf/reports/annualreport/ niwannualreport2014-15.pdf [Accessed January 2019]

[25] United States Environmental Protection Agency. EPANET, https ://www.epa.gov/water-research/epanet [Accessed January 2019]

[26] Kernan, R et al. Demand side management of an urban water supply using wholesale electricity price. Appl. Energy 2017;189:395402.

[27] UK Water Projects 2009. Project Alpha, http://www.waterprojectsonline.com/case_studies/2009/NIW_Alpha_2009. pdf []Accessed January 2019]

[28] NI Water. Silent Valley information leaflet,https://www.niwater.com/sitefiles/resources/pdf/ silent-valley-information-leaflet.pdf [Accessed January 2019]

[29] Bingham, I. Response to enquiry. NI Water ref. 1415272. 2014. 